\title{
Exploration on the Reform of Doctoral Candidates' Training Mode in the Perspective of System Theory --- Taking Jiangsu University as an Example
}

\author{
Youling Wan*, Hui Cao, Huiling Wu \\ Department of Graduate, Jiangsu University, Zhenjiang, China
}

Email address:

wanyouling@ujs.edu.cn (Youling Wan)

*Corresponding author

\section{To cite this article:}

Youling Wan, Hui Cao, Huiling Wu. Exploration on the Reform of Doctoral Candidates' Training Mode in the Perspective of System Theory --Taking Jiangsu University as an Example. Science Journal of Education. Vol. 6, No. 5, 2018, pp. 116-122. doi: 10.11648/j.sjedu.20180605.11

Received: September 28, 2018; Accepted: October26, 2018; Published: November 28, 2018

\begin{abstract}
Aims: Doctoral candidates are at the highest level of higher education, and their training quality is essential. Therefore, the present work is to explore the novel training modes about the doctoral candidates. Methods: Taking Jiangsu University as an example to analyze and explore. Results: the author makes a systematic and comprehensive analysis of doctoral training mode, reform measures from the systems of the funding training, educating and learning, the international joint education, doctoral tutor assessment, training process diversion. Furthermore, the author explores the reform ideas and measures to deepen the training mode of doctoral candidates. Conclusion: all the innovative measures will have a great practical significance to improve the quality of doctoral students.
\end{abstract}

Keywords: Doctoral Candidates, Training Mode, Training Quality, System Reform

\section{Introduction}

As an important part of higher education, training doctoral candidates is designed to cultivate comprehensive talents, create high-level research achievements and render high-quality public service [1]. The State Council of China published an announcement named "Plan to Drive Construction of First-class Universities and Disciplines" in October 2015. This document outlined and confirmed government's view of the vital significance of training high-quality doctoral candidates. It also advocated the concept of laying roots of cultivating students in morality [2]. Subsequently, another bulletin, "To Deeply Reform and Refine the Doctoral Training Mode and Improve Educational Quality", was distributed by Provincial Education Department of Jiangsu in December 2015 and asked doctoral stations to acquire a great progress in the reform of doctoral student's cultivation and training [3]. As a provincial university, Jiangsu University attaches great importance to the quality of doctoral training. Recently, it has carried out the reform of the doctoral training model based on the characteristics, mission and vision of the university. It has introduced a number of practical measures to form a comprehensive doctoral training system. The university has completely finished the task of reform request published by Provincial Education Department and won many national and provincial teaching achievement awards. These remarkable accomplishments have had a wide impact in China and have been fully acknowledged by provincial leaders and other academics. The author explores the reform ideas and measures to deepen the training mode of doctoral candidates in order to provide meaningful guidelines to other provincial universities.

\section{Reform Ideas and Measures}

\subsection{Active Establishment of the Sophisticated System of Supportive Funding}

According to the requirement of the "Advice on Improving the Investment Mechanism for Postgraduate Education" [1] announced by Ministry of Finance, the National Development and Reform Commission and the Ministry of Education, in 2014, the national standard of educational investment on post graduates and doctoral candidates, Jiangsu University 
published "Interim Administrative Measures on Financial Aid for Postgraduate Students of Jiangsu University", in which a group of university, disciplines, colleges and supervisors were successfully established, namely " $3+1.5+X$ " incentive system. This system has subsequently been reformed and improved. In addition, it is estimated a single candidate can be awarded up to $¥ 200,000$.

\subsubsection{Regular Grants}

All the non-directional candidates are supported at least $¥ 30,000$ every year. This project contains national fund of $¥ 13,500$ every year, academic scholarships for freshmen of $¥ 25,000$ for the first year and academic scholarships of $¥ 15,000$ for the second, third and fourth year, respectively.

\subsubsection{Allowance from Supervisor}

According to regulation of fund for non-directional doctoral candidates, assistant allowance of $¥ 5,000$ is rendered to students from medical, scientific and engineering fields and at least $¥ 2,500$ to humanity and social students. However, most candidates enjoy a higher subsidy given by supervisors than university standard. Based on a survey among more than 300 participants, a great proportion of students are given allowance by supervisors ranging from $¥ 1,500$ to $¥ 2,000$ every month and each of students at least receives $¥ 1,000-1,200$ according to the published data of the financial department of the Jiangsu University in 2017. Moreover, a wide range of candidates can be rewarded by supervisors at the end of every year for $¥ 5000$ each student. It is calculated that each candidate can get allowance ranging from $¥ 15,000$ to $¥ 17,000$.

\subsubsection{Additional Funds}

Jiangsu University has set diverse research funds, including fund on scientific research and innovative projects, fund on graduates' studying abroad and fund on outstanding thesis. Moreover, some special disciplines also cooperate with companies and provide specific fund to students. All these reform efforts and incentives can basically benefit all candidates.

\subsection{Implementation of the System of Combining Educating and Learning}

\subsubsection{To Revise of "Management of Enrollment Allocation of Doctoral Candidates in Jiangsu University"}

The whole university insists performance-oriented principle and endeavors to develop based on changing situations and "the main factors and indicators of the enrollment scale of doctoral students in universities", which is published by Ministry of Education. A complete system for educational evaluation, including research grants, talents group, research platform, scientific effectiveness and training scale, has been successfully established. The enrollment allocation is taken into consideration to assess cultivating quality and training condition [4]. By doing this, feedback can be expresses timely and thus incentive and punishment for enrollment can be carried out effectively. For example, in 2017, supervisors with high-level training achievements are allowed to enroll the other 13 students except for the numbers reserved by the university, which has broken the equal enrollment of each school.

\subsubsection{The Annual Qualification Examination of Doctoral Supervisors of Jiangsu University}

This implement improved the condition of entrance permission for doctoral supervisors. Doctoral supervisors must meet one of the following requests. The first is to have at least one national fund (with fund no less than $¥ 200,000$ ) or have a national key research. The second is to take provincial researches with cumulative fund up to $¥ 300,000$. The third is to be in charge of a municipal project at the time of qualification examination and the grant for each project must be more than $¥ 500,000$ or is to be working on a horizontal project with grant of $¥ 500,000$. The above requests play an important role in ensuring the adequate research expense and paving the road for doctoral candidates to participate high-level research.

\subsubsection{Publication of "Measures of Reform for the Enrollment of Doctoral Candidates in Jiangsu University"}

This publication provided a compensation for the enrollment of doctoral candidates [5]. Despite of the limit of enrollment for each supervisor, they can apply for extra one candidate to accomplish national and key researches. To do this, supervisors need to pay the compensation cost to university. The demand of supervisor for extra students is met while every candidate can learn and make a difference in actual scientific research.

\subsubsection{Addition of "Temporary Measures for Appointment and Administration of Off-campus Supervisors of Jiangsu University"}

To improve the research ability of doctoral candidates, this document has put forward meaningful measures, including making full use of resources of industrial professors and off-campus supervisors, developing the influence of international experts and specialists on construction of discipline and education of students, getting comprehensive resources inside and outside of university, establishing provincial engineering technology research center and key laboratory and utilize diverse projects to create newly discipline and cross research. Doctoral candidates have greatly improved their research capabilities and levels by participating in projects of off-campus supervisors and industry professors.

\subsection{Introduction of the System of the International Joint Education}

\subsubsection{System of Strategic Safeguard}

The university insists on internationalization as a strategic choice for research university construction. To accomplish missions of internationalization, a series of measures have been planned and published in 2014, for example, "Management of Jiangsu University Students' Exchange Fund" and "Measures to Promote the Implementation of Overseas Study for Students". They require key discipline to take one 
third of doctoral candidates studying abroad at length of more than one year. Moreover, a special fund for international exchange was built and can provide $¥ 5,000,000$ for students to take international examination, such as IELTS and TOEFL, attend international academic conferences and train candidates with other institutions.

\subsubsection{Joint Endeavor of Driving International Education}

The university attaches great importance to internationalization. The president of the university takes the main responsibility of international development, and the department of international department, the postgraduate school, the school of overseas and the department of student affairs play an important role in their own fields. The Department Of International Cooperation and Exchange make overall plans and coordinate to strengthen links with overseas high-level universities and provide students with various overseas exchanges and learning platform [6]. The postgraduate school promotes the students to study abroad based on the reform of course, the identification of credits, mutual degree awarding and other projects. In addition, the Overseas Education College cooperates with the postgraduate school to promote the "assimilation" teaching management system for overseas students, which provides Chinese students precious chances to get multicultural information within campus. The Department Of Student Affairs takes responsibility to enhance the system of incentive. All the departments are in charge for different parts of international education and they have established a perfect platform of internationalization for candidates.

\subsubsection{Financial Aid}

The university regulated publicly that national key disciplines and provincial preponderant subjects must invest at least $5 \%$ of total construction fund on overseas study for doctoral candidates, while other disciplines need to put specific fund onto construction of talent training. All these efforts are to make sure that each candidate is able to achieve international experience and to meet the requirement that at least one third of candidates from national key discipline, provincial preponderant subject and national science and technology platform will be abroad for at least one year.

\subsection{Management of System of Enrollments Allocation}

\subsubsection{Criteria of Selection of Supervisors}

In recent years, the university keeps revising and refining "Method of Selection of Instructional Teachers in Jiangsu University", which requires that the three criteria of selection of supervisors need to be improved. The qualification, research condition and screening process are the main indicators for selection and they have contributed to a success of the improvement of new doctoral supervisors.

\subsubsection{Implementation of the Separation of Evaluation and Enrollment System for Doctoral Supervisors}

Jiangsu University has 280 doctoral supervisors with an annual enrollment of 0.6 doctoral candidates for each supervisor. To enhance the development of supervisors group and make full use of doctoral candidates in research and discipline, the university has kept the qualification of supervisors for five years. Only the supervisor has provincial or national project, he can enroll new candidates and each of them is limited to recruit in first-class discipline. It is $70 \%$ of supervisors who are training doctoral candidates, which results in absolute participation in advanced research for students.

\subsubsection{System of Incentive}

This system means the capacity for supervisors to enroll is dependent on the training quality, platform and achievements [7]. "Reform measures for the enrollment of doctoral students in Jiangsu University" requires that excellent supervisors with high-level research results can independently introduce new candidates. The academicians of the full-time supervisors, China National Funds for Distinguished Young Scientists, Distinguished Professor of Yangtse River Scholar, supervisor of 100 excellent doctoral dissertations, and the leaders of national key (supporting) subject, and preponderant academic leader in Jiangsu can freely choose an candidates. Moreover, the supervisors of the candidates who are awarded with excellent dissertations and published papers on leading journals, such as "Science" and "Nature" can get an additional enrollment for three consecutive years.

\subsubsection{Censorship of Dissertations}

This system implies a great censorship of doctoral dissertations and a meaningful change of life-long mentor. Since the early $1990 \mathrm{~s}$, the university has been adhering to the "double-blind" review for doctoral dissertation. A series of rules, including "Working Procedure of Double-blind Review for Postgraduate Dissertation of Jiangsu University" and "Jiangsu University Graduate Supervisor Regulations", have been published and successfully enhanced the awareness of responsibility of supervisors. Academic degrees committee of Jiangsu University scrutinized and approved "Measures for selective examination of postgraduate dissertation of Jiangsu University" in 2016, which put forward that supervisors can be disqualified or deprived of permission for enrollment and limited on the capacity of enrollment if corresponding candidates' dissertations were below the mark of casual inspection or failed in reexamination[7]. In addition, the discipline for disqualified dissertations will be alarmed and forced to reorganize or limit capacity of enrollment.

\subsection{Promotion of Assessment and Elimination}

\subsubsection{Finalization of Doctoral Length}

This system limits the length of doctoral schooling between 4 and 6 years in 2014. About 100 candidates quitted pursuing doctoral degree because of non-graduation after 6 years from entrance in 2016 and 2017. And for those who was still working on research but also exceeded the time limit, the university forced them to finish research and submit dissertation in one year. This work cleaned a great proportion of blind area of management and played a good role in supervising the cultivation quality of doctoral students and the 
progress of thesis work.

\subsubsection{Classification of Doctoral Candidates}

Comprehensive revision of doctoral training program is guided by three principles, which are to set up advanced concepts and encourage reform and innovation, to refine various standards and promote ability improvement, to give top priority to quality and serve social needs. The new training program claims that each doctoral candidate needs to finish comprehensive examination (including written test and interview) before dissertation proposal, which will rank students based on three levels (excellent, normal and suspended). $15 \%$ of all candidates will fail in proposal and the last one of candidates from the disciplines with smaller student capacity will fall in suspend. This compulsive system of classification has successfully managed training students and ensured the quality of cultivation.

\subsubsection{Management of Degree Quality}

In 2013, the school revised the "Regulations on the Publication of Academic Papers by Graduate Students during the Period of Postgraduate Study in Jiangsu University" to comprehensively improve the requirements for doctoral students to publish academic papers and other scientific research results. The evaluation of doctoral dissertation has strictly performed as "Interim Measures for the Blind Review of Postgraduate Thesis of Jiangsu University" and insists a $100 \%$ "zero interference" double-blind trial system. In addition, the university manages and controls the quality of doctoral students' entrance and graduation according to strict degree management.

\subsubsection{Academic Misconduct "Zero Tolerance"}

Referring to the "Measures for the Treatment of Misconduct in Dissertation" (Order No. 34 of the Ministry of Education) [8], the university has successively formulated the "Jiangsu University Graduate Academic Ethics Standards (Trial)" and "Jiangsu University's Measures on the Treatment of Misconduct of Dissertations". The rules and regulations required by the series of academic ethics regulations clearly stipulate that the degree applicants who have fraudulent behaviors shall be given disciplinary action according to the administrative measures of the Ministry of Education and the graduate students whose degree is cancelled will be announced to the public. The instructors who fail to perform academic ethics and instruct formal education or there is false and plagiarism in dissertation, the university will give them the corresponding administrative sanctions. If the fraud behavior is highly serious, the university will reduce the enrollment of the corresponding disciplines and majors of the relevant colleges and give who is in charge of appropriate punishment [9].

\subsubsection{System of Quality Supervision and Guarantee for Doctoral Candidates}

The university has a graduate education supervision team of senior professors with comprehensive discipline and reasonable age structure. On the one hand, it checks the quality connotation involved in the key training links of graduate students. On the other hand, it puts forward reasonable suggestions for postgraduate education through education and teaching research. To guarantee the quality of graduate education is continuously improved [10]. At the same time, the university gives full play to the immediate orientation function, diagnosis function and improvement function of the "postgraduate management information system", and implements the intelligent supervision, diagnosis and early warning of the whole process of the postgraduate course teaching and assessment, practice links and dissertations. Hence an all-around and three-dimensional quality assurance system for graduate education is successfully established.

\subsection{Constant Improvement of "Three-Full" Education System}

\subsubsection{Strong Promotion of Doctoral Curriculum Reform}

Jiangsu University combines the quality of the course with the ideological and political education of doctoral students and pays attention to the improvement of doctoral students' scientific research ability and academic accomplishment. The core curriculum of majority for doctoral students covers the most basic knowledge of the subject and plays a pivotal role in the course study for graduate students [11]. To encourage and support the reform of the core curriculum, the university has set up a special fund for core curriculum since 2016. This fund aims to promote the establishment of core curriculum teaching team which is leaded by the curriculum designer. Based on the integration of and discussion by team members, the curriculum structure will be strengthened, and the teaching content will be more concise. In addition, owing to efforts on exploration in method of interactive teaching and exchange of roles of instructors and students, the level of difficulty and quality of core courses have been largely improved and thus a group of high-level core curriculum has been successfully formed.

\subsubsection{Strict Assessment System for Evaluation of Supervisors' Guidance}

In order to enhance the education quality of supervisors, put the request of "moral education" into practice, and highlight the "first evaluation standard" of supervisors' morality, the university issued the "Implementation of the Graduate Instructors' Responsibility to Achieve Cultivation with Morality of Jiangsu University (Trial)" and the "Standards for the Work of Postgraduate Instructors of Jiangsu University" in June 2018. These regulations stipulate that each graduate student shall anonymously evaluate supervisors' moral education according to the relevant contents of supervisors' responsibility before leaving the university. For the first $1 \%$ and the last $1 \%$ of supervisors from assessment, the university will organize educational managers to conduct comprehensive evaluations by means of individual interviews, group seminars and visiting colleges, and to propose work experience or improvement suggestions. The evaluation results will serve as an important evidence for the evaluation of the qualifications 
for supervisors and the selection of excellent instructors. Thus, the effective promotion of the "supervisors as the first person responsible for moral education" is guaranteed from the system and management mechanism.

\subsubsection{Construction of Mental Health Protection System for Graduates}

The Graduate Management Department under Jiangsu University Party Committee and the Graduate School of Jiangsu University cooperate with Mental Health Education Center of Jiangsu University to explore and construct a novel four-level security system for mental health education, namely "university-college-class-project group (dormitory)", in which the last level for students majored in science, engineering and medicine was supervisors team and research group. For students in humanity and social science, the last level was in dormitory. This practice has gradually established a "double closed loop" guarantee system based on the research group and graduates' dormitory and aimed to the problems of mental health education in every level. In other words, it is expected to solve the fundamental mental problems and to ensure the mental health for doctor candidates in terms of the study, research, daily life, emotion and employment. All the efforts are a firm proves for Jiangsu University to be a prominent family of both education and caring.

\subsubsection{Beautification of Culturally Educational Atmosphere}

To create a good academic environment, the university aims to set up a distinctive academic activity for each college and these academic activities will lead campus culture and maintain academic ethics throughout the university [12]. Moreover, the construction of postgraduate case study seminar room, the language lab and the "innovative practice activity center" of our university has been strongly driven according to the principle of harmony between usefulness, aesthetics and pedagogy. Besides, the university enlarged the investment on academic culture construction in the graduate teaching building with the purpose of refining the educational environment for graduates and their cultural taste, enriching their amateur science and technology activities and encouraging them to grow into talents.

\section{Handling of Difficulties During the Reform Process}

\subsection{How to Improve the Ability of Communication with Foreigners for Doctoral Candidates}

A large number of doctoral students have strong research capabilities and ability to write English papers, but oral communication is difficult for them. The university has carried out a comprehensive reform of the doctoral English course since 2014 and has added 2-3 students whose mother tongue is English as teaching assistants in class. Hosting a simulation contest of international academic conferences, Chinese and foreign academic forums, the university spared no efforts to encourage students communicate with overseas students, inspiring doctoral students to synchronize academic English with extracurricular classes. In addition, the university has strengthened the proportion of English and bilingual courses in new training programs. What is more, foreign experts are expected to give lessons to graduates and international academic conferences are encouraged to be host in order to strengthen the training of postgraduate professional English and oral expression skills.

\subsection{How to Effectively Promote Joint Training at Home and Abroad}

First, the university actively promotes graduate students' overseas study programs from the level of supervisors. In 2017, the "Measures for the Examination of the Qualifications of Doctoral Supervisors for Doctoral Supervisors in Jiangsu University" was revised. It is stipulated that doctoral supervisors must recruit at least one graduate student from abroad or one-third of doctoral candidates whose supervisor owing the prominent disciplines in Jiangsu Province need overseas experience more than one year. One-third of doctoral candidates in other disciplines must study abroad for more than three months.

Secondly, at the end of 2016, on the basis of adequate solicitation of opinions and suggestions from various disciplines and colleges, the "Guidelines for Jiangsu University Graduates to Academic Exchanges of Universities and Research Institutions" was published. Each of the dominant disciplines selected around 30 well-known foreign universities with a certain academic reputation in the world to guide doctoral students to communicate with these universities. In May 2017, the university issued the "Administrative Measures for Postgraduate Exchanges and Study-related Funding for Jiangsu University" and issued a special fund to provide key funding for doctoral students to travel abroad for one year or more, meeting the needs of basic life and learning for every doctoral candidate with intention to go abroad.

\subsection{How to Release the Pressure of Scientific Research and Study Undertaken by Doctoral Students}

The $\mathrm{PhD}$ students admitted in 2015 will take part in the new training program for the first time. This year, some disciplines report that after the implementation of $15 \%$ "suspended adoption" system for the comprehensive assessment of doctoral students, the doctoral students' research and academic achievements are very rich, and it is difficult to suspend from outstanding students. Students are also very worried about the results of the comprehensive assessment of the subject and the academic scholarship. Coupled with heavy research and learning tasks, the pressure is huge. The university has discussed that the doctoral students' comprehensive assessment system just began for not so long and decided to take a smooth transition. The eliminated doctoral students in this way will not be disqualified for applying for academic scholarships and this system will be considered after the measures and procedures are optimized. 
In 2017 , the university set up a postgraduate work department of the party committee, which is affiliated with the graduate school. This reform further highlights the ideological and political education of graduate students. Apart from this, valuable experiences of the doctoral students who are immersed in the front line of scientific research are provided and unnecessary mistakes at work will be avoided. In addition, the public has added a "Research and Study" section, in which regularly inspirational and positive energy articles are edited and announced. All efforts are to guide the mental health of the graduates and to ease daily pressure for candidates.

\section{The Influence of Reform of Doctoral Candidates' Training Model on the Comprehensive Strength of Jiangsu University}

The five reformatory measures of the doctoral students' training model in Jiangsu university have enabled each candidate to participate in key scientific research projects during the school year, and keep up with the frontiers of leading development of disciplines. Many doctoral supervisors also require their doctoral students to try to write national research fund reports during their studies. This has been considered as a necessary way to improve postgraduates' ability of research.

Recently the university has been paying more attention to the quality of doctoral student, therefore, the discipline construction, scientific research, and comprehensive strength of the university have been rapidly constructed. In 2017, the university was successfully selected to be one of the first batch of universities for the construction of high-level universities in Jiangsu. Five disciplines (fields) including engineering, materials science, clinical medicine, chemistry and agricultural science entered the top $1 \%$ of ESI, and 4 of them entered the top $5 \%$, tied for 46 th in the country and 7 th in Jiangsu. Three disciplines entered the top 200 in the world of soft sciences. In the early 2018, the comprehensive strength of the university climbed from the $72^{\text {nd }}$ in 2012 to the $39^{\text {th }}$ in the ranking list published by Evaluation of Chinese University. As a new force in the discipline construction and research work, the doctoral student played an indispensable role in the process of construction of high-level universities and world-class universities and world-class disciplines.

\section{The Next Step of Reform and Prospects}

\subsection{Improving Quality of Postgraduate Training Dependent on Dominant Subject Groups and Promoting the Crosstalk Between Different Subjects}

Firstly, based on the dominant disciplines of modern agricultural equipment and others and guided by the national major scientific research and engineering projects, the university plan to strengthen the advantages of interdisciplinary research and combine with the implementation of the Jiangsu Excellent Talents Selection Program to develop a special doctoral training program. Secondly, to promote the graduates from agricultural equipment discipline group to occupy the core industry, the university makes full use of the social resources, such as the signing of a doctoral training agreement on the integration of production and education with large-scale agricultural equipment and state-owned enterprises including Yituo Group and Lovol Heavy Industries. Thirdly, to comprehensively improve the quality of doctoral students' training, highlight the academic strengths and characteristics of the university and serve the university's double-class construction goals, the university has actively promoted the joint training program for doctoral students at home and abroad with strong international universities.

\subsection{Establishing a Scientific, Reasonable Training and Assessment System for Graduate Students}

In the first place, the cooperative mechanism of Jiangsu University will be developed, which means to strengthen the joint efforts from administrative staff of graduates, graduate counselors and candidates' supervisors. Based on this system, the university will further optimize the educational method which covers all members, whole process and all-round aspects and thus implement the doctoral candidates' training requests. This practice is expected to consolidate the upper design, which means the management of system architecture and supervision for training students from the perspective of the authority of the university. In the second place, the assessment of educational quality must come from the employer. It is planned to further improve the "Graduate Management Information System" and to collect employment information for graduates. These efforts include a system of quality tracking and analysis and self-evaluation system for doctoral candidates before and after graduation. This networking and digitization will function as feedback mechanism of both $\mathrm{PhD}$ students' career development and employers.

\section{Conclusion}

The present work takes Jiangsu University as an example to makes a systematic and comprehensive analysis of doctoral training mode, reform measures, which has a great practical significance to improve the quality of doctoral students.

\section{Acknowledgements}

Key project of graduate education and teaching reform in Jiangsu Province, China (JGZZ17_55): The strategic concepts and selected routes of graduate education in the perspective of leading universities. 


\section{References}

[1] Opinion of how to refine the system of investment of postgraduate education. Ministry of Finance, National Development and Reform Commission, Ministry of Education. [2013] 19, 2013.2.28.

[2] Plan to drive construction of first-class universities and subjects. The State Council. [2015] 7, 2015.10.24.

[3] To deeply reform and refine the doctoral training mode and improve educational quality. Jiangsu Provincial Department of Education. [2015] 7, 2015.12.14.

[4] YanTing, Jiang Liguo. Research on the Correlation between Graduate Award System and Graduate Development (Take China University of Petroleum (Beijing) as an example). Journal of Kaifeng Institute of Education, 2016, 5, pp.125-126.

[5] Sun Haitao. Research on the Problems and Countermeasures of College Graduates Enrollment Publicity under the Background of First-class Discipline Construction. Journal of Educational Institute of Jilin Province. 2018,34(07), pp.73-76.

[6] Zhang Ying, Sun He. The Construction and Thoughts of Graduates' Support System Based on Systematic Concept. Journal of Mudanjiang College of Education. 2016,07, pp.24-25.

[7] Zhang Yanping, Lu Jing. Commentary on the Responsibility and Realization Path of Academic Norm Teaching under the Guidance of Supervisors. Journal of Social Science of Harbin Normal University. 2017, 8(03), pp.157-160.

[8] Method of dealing with plagiarism in dissertation. Ministry of Education. 34, 2012.11.13.

[9] Liu Kunpeng, Huang Yan, Yuan Qihai, Feng Wei. Suggestions on the Development of Intellectual Property Management National Defense in Chinese Universities. Defense Technology Review. 2018,39(02), pp.82-85.

[10] Li Dianwei, Deng Chenguang. Thoughts on Improving the Quality of Graduate Education in Local Colleges and Universities. Modern Communication, 2014, 05, pp.256.

[11] Li sheng, Li Yong, Wang Haiyan. Research on Process-based Integrated Management Mode of Applied Talents Quality. Journal of Graduate Education. 2015,05, pp.36-41.

[12] Song Dawei. Research on Financial Aid of Graduate Students in Guangxi University under the Background of Comprehensive Charge System. Journal of Inner Mongolia Normal University. 2016, 29(07), pp.21-23. 